\title{
Phenological and Growth Interactions between Velvetleaf (Abutilon theophrasti M.) and Cotton (Gossypium hirsutum L.)
}

\author{
Cortés-Martín J.A. \\ Instituto de Investigación y Formación Agraria y Pesquera \\ Alcalá del Río, Sevilla, Spain \\ Tel: $34-95-504-5530$ \\ Mendiola-Ubillo M.A. \\ Departamento de Producción Agrícola, Cátedra de Botánica
}

Escuela Técnica Superior de Ingenieros Agrónomos de Madrid, Spain

Tel: 34-91-336-5738

Castejón-Muñoz M.

Instituto de Investigación y Formación Agraria y Pesquera

Alcalá del Río, Sevilla, Spain

Tel: 34-95-504-5530Ｅ-mail: mercedes.castejon.ext@juntadeandalucia.es

\begin{abstract}
The phenology and growth of $A$. theophrasti in competition with cotton, and the influenced of weed sowing time and weed plant density on phenology and growth were examined in several field studies conducted over the period 2000-2002. A. theophrasti was found to produce three cohorts that emerged in a staggered manner from April 21 to June 20. The first cohort emerged simultaneously with cotton under a plastic cover and the second by the time cotton plants had 5-6 true leaves. Flowering in these two cohorts started at 572-594 growing degree-days (GDD), boll ripening (stage $\mathrm{H}$ ) at 800-885 GDD and boll drying at 1020-1037 GDD.

Velvetleaf and cotton cotyledons were formed simultaneously at all weed sowing densities. Also, plant height of $A$. theophrasti increased with increasing density, whereas cotton height decreased due to shad and competition.
\end{abstract}

Keywords: Abutilon theophrasti, Cotton, Phenology, Velvetleaf, Sowing date

\section{Introduction}

Like cotton (Gossypium hirsutum L.), velvetleaf (Abutilon theophrasti Medicus) is an annual weed belonging to the family Malvaceae. This weed has infested a number of irrigated crops (including: cotton, maize, potato, sunflower and, more later citrus, peaches and asparagus) in the basin of river Guadalquivir in southern Spain (Cortés-Martín et al., 1998). Velvetleaf has posed serious problems to cotton growers since its introduction into this region in the early 1980s. Cotton which accounts for largest area of production in Andalisia due primarily to its high economic value (Rodriguez and Carnero, 1990) is currently the crop most severity affected by $A$. theophrasti in Andalusia. By the late 1990s, roughly $32 \%$ of all cotton cultivated land in the region was infested with velvetleaf. The significance of this weed arises from its ability to easily colonize previous crops and form increasingly dense patches along field boundaries river banks, and also within crops.

The agronomic problems caused by velvetleaf result from intense competition due to its high spreading and colonizing ability, and the capacity to form persistence in soil seed bank (Toole and Brown, 1946). This weed proliferates in nutrient-rich, well-fertilized soils (Izquierdo and Casas, 1986), where a single specimen can produce up to 8000 seeds capable of retaining their viability for 40-50 years (Spencer, 1984). Also, its infrutescences can spread to other crops via irrigation water and prosper especially well in silty soils (Saavedra et al., 1995).

Studies on phenological interactions between velvetleaf and specific crops can provide valuable clues with a view to understanding the effect of the weed on each type of crop and efficiently adjusting the herbicide rate to 
be used for control purposes (Wax, 1997). This information is essential to properly manage the weed taking into consideration weed control costs (McDonald and Riha, 1999). Although few references to its phenological interactions with cotton have been reported to date, some studies on its interaction with maize (Calvet and Recasen, 1993) and its morphological properties (Lindquist and Mortesen, 1999) have previously been conducted.

The density of the weed and its emergence date influence its growth cycle and the way it affects crops as they result in temperature and moisture conditions departing from those of normal seasons (Zanin et al., 1988). In northern Spain, the nascence period for maize-infesting velvetleaf spans from mid May to early July each year, where the weed produces two different cohorts with nin-synchronous growth cycles (Calvet and Recasen, 1995). This behaviour is similar to that observed in velvetleaf populations naturally infesting soybean (Czimber et al., 1990) and maize crops (McDonald and Riha, 1999) in New York. In addition, the stages of velvetleaf are highly sensitive to the particular photoperiod (Patterson, 1995); thus, an increased delay in weed germination results in decreased weed height, and decreased length of time for the first flower to emerge and bolls to ripen (Sato et al., 1994).

The high latency and staggered nascence of velvetleaf (Saavedra et al., 1995) make it difficult to effectively eradicate this weed once it has reached the soil seed bank.

The purpose of this work was to examine the phenological and developmental stages of velvetleaf in cotton in the basin of river Guadalquivir (southern Spain), and to understand the influence of weed density and emergence date on crop yield. Linkages between climatic conditions and their influence on weed development are also discussed.

\section{Materials and methods}

\subsection{Phenological interaction over time}

Development of a velvetleaf population produced by artificial infestation at the time of crop sowing

In order to confirm whether velvetleaf would emerge in a staggered manner in a cotton field (Calvet and Recasen, 1993), in 2000 we conducted a study of the weed and crop on the Las Torres farm, which is located in Alcalá del Río (Sevilla), a municipality in the basin of river Guadalquivir. The soil, which was silt loam in texture and free of velvetleaf seeds, was uniformly infested with weed seeds collected during the previous spring. The latency of the seeds was suppressed prior to sowing by heating in a water bath at $70{ }^{\circ} \mathrm{C}$ for $5 \mathrm{~min}$ (Khedir and Roeth, 1981).

Velvetleaf and cotton seeds were sown simultaneously on April 15, 2000. The cotton seeds (var. Crema) were sown at the typical depth for this crop $(2 \mathrm{~cm})$ and a rate of $30 \mathrm{~kg} \mathrm{ha}^{-1}$ by using a conventional drill in order to obtain a density of $20 \mathrm{pl} \mathrm{m}^{-2}$. The weed seeds were deposited at a rate of 60 seeds $\mathrm{m}^{-1}$ by hand on the soil surface near the cotton seeds and subsequently thinned out immediately prior to covering with a plastic.

Sowing under plastic was a usual practice in the Guadalquivir basin, where it was used to protect emerging cotton plants from low temperatures, provide uniform nascence, decrease germination time and shorten the crop cycle. The plastic requires periodicaly piercing and slitting in order to avoid overheating on very sunny, hot days, where temperatures can be as high as $40-45^{\circ} \mathrm{C}$ (especially in May). The plastic is usually removed $25-31$ days after sowing (DAS), depending on the particular climatic conditions, in order to avoid suffocation or burning through excessive contact with cotton plants.

The test plot consisted of four furrows $38 \mathrm{~m}$ long each that were split into elemental plots $8 \mathrm{~m}$ in length and $2 \mathrm{~m}$ from each other. The plots were freed of all weeds except velvetleaf by pre-sowing with 0.51 of trifluralin per hectare and weeding by hand as required. Once velvetleaf plants emerged, they were thinned out to $2-4$ leaves in order to obtain an infestation density of $2 \mathrm{pl} \mathrm{m}^{-2}$, which is typical for the study area and results in no significant differences in phenological development of the plants.

Each studied plot was sampled on a weekly basis from April to late August, a total of 32 plants of velvetleaf and as many of cotton being collected in four replications. The data recorded in each sampling operation included the phenological stage of the weed and crop, number of leaves per plant in the growth stage and plant height. Once the reproductive stage started, 100 fruiting organs were harvested at random in order to determine the proportion present at each phenological stage.

The phenological stages of cotton were established in accordance with Alvarado M. (private communication-vegetal health service-), and those of velvetleaf according to Cortés and Castejón (2004), as follows:

(a) Cotton. A Seed, B hypocotyl, $\mathbf{C}$ cotyledons, $\mathbf{D}$ first true leaves, $\mathbf{E}$ buds, $\mathbf{F}$ white flower, $\mathbf{G}$ small bolls, $\mathbf{H}$ large bolls and I open bolls. 
(b) Velvetleaf. A Ungerminated seed, B Radicle emergence, Co cotyledons, D1 1-2 true leaves, D2 3-5 true leaves, D3 more than 5 true leaves, E first closed buds, $\mathbf{F}$ flowers, $\mathbf{G}$ growing fruits, $\mathbf{H}$ ripening fruits and seed thickening, and I dry bolls and seeds.

\subsection{Influence of weed sowing time}

Based on the fact that velvetleaf exhibited staggered emergence in a cotton field in 2000, we examined the effect of the weed sowing date in order to determine the influence of the emergence date of the weed on the crop, its growth and its flowering and fruiting periods. To this end, we studied the following velvetleaf sowing times:

(a) Early sowing, simultaneous with cotton and following irrigation of the soil in order to lower its temperature and facilitate emergence of the crop.

(b) Late sowing (15 days post cotton sowing). Care was exercised to reproduce the weed nascence pattern observed following removal of the plastic cover 25-30 days after the crop was sown, by effect of any rain water potentially falling in the second half of spring (May), or the irrigation water applied in the absence of rainfall.

(c) Very late sowing, 45 days latter than cotton, which was close to the date where heavy irrigation was for the first time applied to the crop.

Cotton and velvetleaf seed were sown jointly on April 14-16, 2001 at Coria and Los Rosales respecrively, and on April 21-22, 2002 at Los Rosales and Coria, respectively. Cotton was sown with a conventional drill, using the Crema 111 variety at Los Rosales and the Bravo variety at Coria. Seeds were sown at the typical depth for the crop $(2 \mathrm{~cm})$ and a rate of $30 \mathrm{~kg} \mathrm{ha}^{-1}$ in order to obtain a density of $20 \mathrm{pl} \mathrm{m}^{-2}$. Velvetleaf seeds were deposited by hand at a rate of 60 seeds $\mathrm{m}^{-1}$ on the soil surface near the cotton seeds prior to covering with plastic, and subsequently thinned out.

The test plots were managed as described in the previous section, and the specific phenological stages examined were those previously identified by Cortés and Castejón (2004).

\subsection{Influence of climate on velvetleaf phenological development}

The data recorded during the tests included rainfall and temperature as obtained from the weather station at each study site. The highest and lowest temperatures were used to calculate the cumulative heat requirements for proper development of the cotton crop, using the following equation:

$$
G D D=\left[\left(T_{\max }-T_{\min }\right) / 2\right]-T_{\text {thre }}
$$

where GDD denotes growing degree-days and $T_{\text {thre }}$ the threshold temperature. GDD was determined for the period from velvetleaf emergence (Sato et al., 1994) to crop harvest. The threshold temperature used for the weed was $10{ }^{\circ} \mathrm{C}$ (Steinsiek and Oliver, 1982) rather than the $15.5^{\circ} \mathrm{C}$ typically employed to model cotton (Asgrow Cotton Program 1999, private communication). The previous data for the two sites and years were used to obtain GDD regression curves and calculate the cumulative proportions for the most salient phenological stages of velvetleaf.

\subsection{Influence of velvetleaf sowing density on its phenology and on cotton growth}

These variables were studied in tests performed on soil free of velvetleaf seeds on the Los Santos (Los Rosaales) and Santa Eufemia farms (Coria del Rio) over the period 2001-2002, using the methods described in Section 1. The test plots consisted of 23 furrows $38 \mathrm{~m}$ long each that were split into 4 elemental plots $8 \mathrm{~m}$ in length and $2 \mathrm{~m}$ from each other. After emergence, weed plants were thinned out to the desired density (viz. 0, 1, 2, 5, $11 \mathrm{or} 25 \mathrm{pl}$ $\mathrm{m}^{-2}$ ). The elemental plots sown at a weed density of 5, 11 or $25 \mathrm{pl} \mathrm{m}{ }^{-2}$ consisted of one furrow; while, those sown at 1 or $2 \mathrm{pl} \mathrm{m}^{-2}$ consisted of four furrows as they were intended to provide an adequate number of weed plants for sampling. Each elemental plot was sided by two guard rows intended to prevent mutual interferences.

Plots were sampled on a weekly basis from April to late August in order to collect a total of 32 plants of velvetleaf and 32 of cotton in four replications. The data recorded in each sampling operation included the phenological stage of both species, number of leaves in the growth stage and plant height.

\section{Results}

\subsection{Phenological interference over time}

Development of a population of velvetleaf produced by artificial infestation at crop sowing time.

Figure 1 shows the phenological stages of velvetleaf and their duration in Alcalá del Río in 2000. As can be seen, velvetleaf initially emerged simultaneously with cotton under the plastic cover in the second half $\left(23^{\text {rd }}\right.$ day) of April. The first true leaf was seen 12-13 days after sowing (DAS), when the weed plants were shorter than the 
cotton plants. By early May (17 DAS), the weed population included plants with 2 (D1) and 3 leaves (D2); on the other hand, cotton plants continued to have 2 true leaves (D2) and had started to develop the next leaf node.

At the time the plastic cover was removed on May 15, 2000 (viz. 30 days after cotton was sown), most velvetleaf plants had 3-5 leaves (D2) (Fig. 1); however, a few, at a later phenological stage where the stem had started to elongate, had as many as 6-7 (D3). In the second half of May, cotton plants had 2-3 leaf nodes (with 4 true leaves and a third node bearing incipient leaves). In addition, a number of velvetleaf seedlings from cotyledons constituting a second cohort emerged as a result of sprinkler irrigation 10 days before (on May 5). Together with the first cohort, this second ensured staggered germination of velvetleaf between cotton plants.

The earliest floral buds (E) of velvetleaf appeared in late May on plants that emerge in the first cohort, which had 9-10 leaves, however, the weed population comprised plants at various vegetative stages with some only having 4-5 leaves (D2) and others with 7-8 leaves and elongating stems (D3) (Fig. 1). Most cotton plants had 8 true leaves, so the weed produced floral buds earlier than did the crop. However, the older plants (i.e. those at the floral bud stage) coexisted with some seedlings at the cotyledon stage. The onset of the flowering period in velvetleaf (F) signalled the beginning of its reproductive cycle; this was clearly seen in the samples collected on June 9, coinciding with the formation of floral buds (pin squares) in cotton (E) (Fig. 1). At that time, however, most velvetleaf plants were at the floral bud stage (E) and coexisted with plants bearing 7-8 leaves (D3).

Velvetleaf seedling at the cotyledon stage were again observed in the sampling that occurred on June 17 due to an irrigation being applied on June 4-5 (Fig. 1). Velvetleaf seedlings at the cotyledon stage coexisted with older weed plants at the boll growth (G) (Fig. 1), floral bud (E) and open flower (F) stages. This emergence produced the third cohort of seedlings.

The earliest ripening velvetleaf bolls $(\mathrm{H})$ were seen at the onset of flowering $(\mathrm{F})$ in cotton, which exhibited its first white flowers at the time (Fig. 1). In that sampling, the general weed population exhibited fruiting organs in their buds (E) in addition to some open flowers (F). The youngest velvetleaf plants had 2 leaves (D1) or 3 to 4 (D2). The plants constituting the third cohort were buried as a result of an inter-row cultivation prior to an irrigation in early July. As recorded on August 23, the weed population was at the end of the ripening stage (H).

The boll drying stage (I) in the velvetleaf plants in the first cohort lasted from July 15 to August 28, where the cotton plants exhibited their first open bolls (I) and some plants with large bolls still remained (H).

\subsection{Influence of weed sowing time}

Figures $2 a$ and $2 b$ illustrate the phenological development of velvetleaf sown in a staggered manner 15 and 45 days, respectively, later than cotton. The figures show the average values for the years 2001 and 2002 at the onset of each particular phenological stage of the weed, the time of year where each stage fell and the period over which each prevailed.

The second weed cohort exhibited delayed phenological stages with respect to the first: (Co), (D1), (D2) and (D3). This can in principle be ascribed to the first cohort gathering more GDD under the plastic cover, and also to the second cohort meeting with competition from the previously emerged crop. Differences between the two cohorts decreased at stages $\mathrm{E}$ and $\mathrm{F}$, and reduced to 10-12 days by the end of the cycle (stage I, dry bolls).

The third cohort exhibited a much greater delay in its early phenological stages; also, as stated above, seedlings soon disappeared by effect of the soil being earthed up prior to irrigation of the furrows in early July.

The presence of three cohorts at Coria del Río and Los Rosales provided a global picture of the weed populations present in the marshlands and plains of river Guadalquivir. Figures $3 a$ and $3 b$ show the general population of velvetleaf (GPABUTH) formed by the three cohorts. The weed population exhibited staggered nascence over the period from April 21 to June 20 (i.e. 61 days) and hence spanning the three velvetleaf cohorts.

The disappearance of velvetleaf cotyledons in the three cohorts occurred 12-13, 14-15 and 20-21 days after emergence (DAE). Unlike the plants in the second and third cohorts, those in the first cohort were under the plastic cover over such a period. The length of the latest two periods required for cotyledons to disappear is consistent with that previously reported by Calvet and Recasens (1995), who found velvetleaf to require 14-20 DAE to complete its cotyledon stage in a maize field in the open air.

The first two cohorts of velvetleaf exhibited plants with 3-5 leaves (D2) from April 28 (Coria del Río) to June 21 (Los Rosales); the latter date coincided with the formation of floral buds in cotton. Those plants in the third cohort that reached stage D2 were buried by effect of the soil being earthed up in late June, when cotton was starting to form small bolls.

The earliest floral buds (E) in the first cohort of velvetleaf appeared 41 DAE (i.e. between May 27 and June 15); on the other hand, those in the second cohort formed 35 DAE (i.e. from June 10 to 23), while cotton was forming 
buds and a few plants exhibited open flowers. The bud stage (E) in velvetleaf prevailed for about 54 days (until late July in the Gudalquivir marshlands and early August in the plains) and ended when plants withered (on August 15 in the marshlands and August 22 in the plains). At that time, cotton plants were mostly at the large boll (H) or frequent open boll (I) stage.

The onset of the flowering stage signalled that of the reproductive period, which spanned from June 7 to 24 in the first cohort (52.3 DAE on average ); at the time, the crop had started to form floral buds (Fig. 3a -3b). In the second cohort, flowering began between June 23 and July 3 (46 DAE on average), once cotton had started to form small bolls. Velvetleaf exhibited open flowers from June 7 to August 22, its average period with flowers lasting 60 days (Fig. 3).

The earliest growing fruits of velvetleaf $(\mathrm{G})$ in the first cohort at Coria del Río were seen on June 14 (i.e. 59.3 DAE), coinciding with the appearance of the earliest flowers in cotton. This stage lasted from June 14 to August 28 in velvetleaf (i.e. 70 days on average). However, neither the open flower stage (F) nor the boll development stage $(\mathrm{G})$, where the calyx was at a smaller height, prevailed at any time because plants in the floral bud stage (E) predominated in number and duration.

The boll ripening stage $(\mathrm{H})$ in the first cohort of velvetleaf lasted from June 28 to July 13 (73 DAE on average), coinciding with the formation of the first large bolls of cotton - the plants with which coexisting in the middle of the floral bud (E), flowering (F) or small boll formation (G) stage. In the second cohort, stage $\mathrm{H}$ lasted from July 13 to 27 (66 DAE on average). In velvetleaf, stage $\mathrm{H}$ lasted an average of 45 days (from June 28 to August $28)$ in the Guadalquivir basin; such a period fell within that of large boll formation $(\mathrm{H})$ in cotton.

Boll drying (I) in velvetleaf started 82 DAE on average (July 9-25), a time at which cotton exhibited substantially increased formation of large bolls $(\mathrm{H})$. This phenological stage of the weed invariably started earlier in the marshlands than in the plains. In the second cohort, stage I started between July 7 and August 3, so it overlapped with the start in the first cohort. These two cohorts exhibited boll drying for 32 and 34 days, respectively, their drying periods overlapping and giving an average length of 40 days for velvetleaf (July 9 to September 4); the latter date coincided with the presence of cotton plants spanning the stages from small boll formation to earliest open bolls.

\subsection{Influence of climate on velvetleaf phenological development}

Application of the first thermal integral to the first and second cohorts of velvetleaf in the plains and marshlands, using a threshold temperature of $10{ }^{\circ} \mathrm{C}$ as recommended by Stoller and Wax (1973) and an emergence for the infested crop in accordance with Sattin et al. (1992), provided the two GDD series shown in Table 1. As usual in cotton growth models, we used open-air temperatures.

The GDD value at the start of the flowering stage (F) of velvetleaf in the cotton crop ranged from 572 to 594 GDD (Table 1). These values are close to that reported by Benvenutti et al. (1994) for the same weed in the absence of crop (610 GDD) and differ from that obtained by Sattin et al. (1992) in a maize crop (500 GDD). The average number of GDD needed for velvetleaf to reach stage $\mathrm{F}$ in the cotton field accounted for $34 \%$ of the weed cycle spanning up to complete boll drying and is close to the value obtained by Sattin et al. (1992) in a maize crop (30\%). Plant height, leaf surface area and biomass formation in the weed increased rapidly, and velvetleaf exhibited strong competition with cotton, until weed flowering.

Velvetleaf fruits in the cotton field started to ripe at 880-885 GDD, which coincides with the value reported by Benvenutti et al. (1994) and differs from that obtained by Sattin et al. (1992) in a maize crop (650 GDD). On the other hand, the value obtained at the end of the ripening period was close to $1700 \mathrm{GDD}$; by contrast, Sattin et al. (1992) obtained a value of $c a .1600$ GDD in a maize crop in northern Italy.

Fruit drying started above 1000 GDD (specifically, at 1020-1037 GDD), which is significant because it coincided with the time the weed was resown.

From the start of the flowering period, and for slightly over 1000 subsequent GDD (65-70 days under the conditions of our study), velvetleaf produced abundant buds, flowers, growing fruits and seeds which ripened within a short time and dried to provide effective resowing material and a substantially increased seed bank over a long period.

The variation patterns for the frequencies of the different phenological stages as a function of GDD exhibited the correlations illustrated in Fig. 4, where the $x$-axis shows GDD for the different phenological stages of each cohort and the $y$-axis the weekly frequencies for each stage as cumulative percentages. Data was fitted to third and fourth order polynomials, sigmoids and sinusoids with correlation coefficients, $r$, of $0.98-0.99$. The estimated parameters in the equations express the relationship of the phenological development of velvetleaf to 
temperature (in GDD units). This way of modelling the weed allowed its phenological stage on each date to be identified with provision for this climatic factor.

Thus, at the phenological stage of velvetleaf where application of the post-emergence herbicide failed to effectively control the weed owing to the presence of a substantial number of elongating plants (D3) that might tolerate it, the treatment should not be delayed beyond 200 GDD for the first cohort. In such a case, stage D3 would not exceed $10 \%$ of the weed's lifetime, whereas the rosette stage (D1 + D2) would occur during $60 \%$ of such a lifetime. According to Sattin et al. (1992), velvetleaf is difficult to eradicate from maize fields simply by applying a herbicide to weed plants older than 250-300 GDD.

A similar reasoning could be used with the prediction model for any other stage of interest (e.g. flowering, after which competition from the weed is stronger, or seed drying, after which seeds fall to the ground and start the resowing cycle).

\subsection{Influence of velvetleaf sowing density on its phenology and on crop growth.}

\subsubsection{Relationship between the sowing density of velvetleaf and its phenology}

Monitoring the phenological development of the two velvetleaf cohorts at a density of 1, 2, 5, 11 and $25 \mathrm{pl} \mathrm{m}^{-2}$ in cotton crops in the marshlands and plains of river Guadalquivir revealed that cotyledons appeared simultaneously in both species irrespective of the sowing density of the cohorts. Also, after cotyledons formed, the weed was present simultaneously at various phenological stages in both cohorts and study areas.

The weed plants sown at a density of 1 and $2 \mathrm{pl} \mathrm{m}^{-2}$ evolved virtually synchronously and faster than at the other densities. By the time stage D3 (viz. plants with 6 or more leaves) was reached, the plants sown at 11 and $25 \mathrm{pl}$ $\mathrm{m}^{-2}$ exhibited a marked delay with respect to the others in both cohorts and study areas.

At the start of the flowering stage (F), the first cohort continued to exhibit the previous delay at the highest densities as a result of intraspecific competition. The delay decreased by the time fruits started to dry (I); it was especially apparent in the plants of the second cohort sown at the highest densities relative to those sown at the lowest ones and amounted to approximately one week at the time boll drying started.

\subsubsection{Interactions between growth in velvetleaf and cotton}

Broadly speaking, plant height in velvetleaf and cotton changed with the weed sowing density (see Figs $5 a$ and $5 b$, which show the variation of plant height throughout the life cycle from the time the two species were simultaneously sown to that cotton was harvested).

The mean height reached by the weed plants increased with increasing plant density through increasing intraspecific competition at the highest densities $\left(11\right.$ and $\left.25 \mathrm{pl} \mathrm{m}^{-2}\right)$.

In the absence of velvetleaf, cotton plants reached $90-120 \mathrm{~cm}$ depending on the particular cultivar, site and year. Competition of the weed at a density $2 \mathrm{pl} \mathrm{m}^{-2}$ with the crop resulted in cotton plants shorter than $90 \mathrm{~cm}$ at Coria and $120 \mathrm{~cm}$ at Los Rosales.

Above a velvetleaf density of $5 \mathrm{pl} \mathrm{m}^{-2}$, where the shading effect of the weed was substantially stronger, the height of the cotton plants was 30\% smaller than in the absence of weed.

The height of the cotton plants decreased with increasing velvetleaf density through increasing competition from the weed. Once velvetleaf started to reach its typically large height by the end of the second half of June, cotton growth was arrested. This was clearly apparent at the weed densities 11 and $25 \mathrm{pl} \mathrm{m}^{-2}$, which resulted in strong shading of the cotton plants and prevented them from reaching their typical height; this is just the opposite effect the weed was seen to exert on a maize crop by Sattin et al. (1992).

Based on the foregoing, velvetleaf formed three distinct cohorts; the third, however, was buried by effect of the soil being earthed up prior to irrigation, which was scheduled for early July but was in fact performed in late June. By contrast, a study of the weed in a maize crop in Lérida (northeastern Spain) revealed the presence of only two velvetleaf cohorts or emergence flows (Calvet and Recasen, 1993).

\section{Conclusions}

The sequential emergence of velvetleaf in a cotton field spanned a period of 61 days (from April 21 to June 20). The weed formed three cohorts of which only two reached term. This accounts for the fact that strongly infested cotton fields require up to 2-3 manual weeding in especially unfavourable years and before the mechanic work.

Under a plastic cover, the first velvetleaf cohort emerged simultaneously with cotton and the second by the time the crop plants had 5-6 true leaves. 
In both cohorts, flowering started at 572-594 GDD (viz. from June 7 to July 3). Overlap between the two cohorts resulted in a flowering period of 60 days on average that throughout the months of June, July and August.

Boll ripening (stage $\mathrm{H}$ ) started at 880-885 GDD in both velvetleaf cohorts, which coexisted at this stage for 45 days, from the end of June to the end of August.

Boll drying started at 1020-1037 GDD in both weed cohorts (from July 9 to 27 in the first). Overlap between the two resulted in a boll drying period of 40 days on average during which an overall 700 GDD was gathered.

As regards the influence of the sowing density of the weed on its phenology, cotyledons appeared simultaneously in velvetleaf and cotton irrespective of the particular sowing density. At 1 and $2 \mathrm{pl} \mathrm{m}^{-2}$, weed plants grew synchronously and faster than those sown at higher densities. On the other hand, plants sown at 11 and $25 \mathrm{pl} \mathrm{m}^{-2}$ exhibited a substantial delay that persisted at the start of flowering (stage F) and decreased by the time fruit drying (stage I) began - the delay with respect to the other plant densities at such a time was only one week.

The mean height of the weed plants decreased with increasing sowing density. Conversely, the height of the cotton plants decreased through shading and competition from the weed. At velvetleaf densities above $5 \mathrm{pl} \mathrm{m}^{-2}$, the cotton plants were more than $30 \%$ shorter than in the absence of weed.

The results of this work can be highly useful in studying competition between velvetleaf (A. theophrasti) and cotton, and estimating the economic damage threshold (EDT), with a view to developing an effective phytosanitary strategy towards stopping the steadily growing infestation of irrigated crops by this weed in the basin of river Guadalquivir.

\section{Acknowledgements}

The authors are grateful to the Agricultural Research and Training Institute (IFAPA) for access to their facilities and to Pedro Torrent Chocarro for processing graphical data.

\section{References}

Benvenuti, S., Macchia, M., \& Stefani A. (1994). Effects of shade on reproduction and some morphologicals of Abutilon theophrasti M., Datura stramoniun L. and Sorghun alepensis L. Weed Research, 35 283-288.

Calvet, V., \& Recasens, J. (1993). Caracterización fenológica y demográfica de Abutilon theophrasti Médicus como mala hierba introducida en el cultivo del maíz en Lleida. Actas del Congreso de la Sociedad Española de Malherbología, 93-97.

Calvet, V., \& Recasens, J. (1995). Significación y distribución de Abutilon theophrasti M (Malvaceae) en campos de maíz de la provincia de Lleida. Actas del Congreso de la Sociedad Española de Malherbología, $14-15$.

Cortés, J.A., Castejón, M., \& Mendiola, M. A. (1998). Incidencias de A. theophrasti en el Valle del Guadalquivir. Agricultura, Nov.: 924-927.

Cortés, J.A., \& Castejón, M. (2004). Relación (Abutilon theophrasti M.) y algodón (Gossypium hirsutum L.). Umbral de Tolerancia Económica. Ed. Junta de Andalucía. Consejería de Agricultura y Pesca. 123 pp.

Czimber, G., Hováth, K., \& Suke, P. (1990). Velvetleaf (Abutilon theophrasti M.) damage in soyabeans. Acta Ovariensis, 32 21-25.

Izquierdo, I. \& Casas, J. L. (1986). Algunas características de Abutilon theophrasti M como mala hierba introducida en Lérida. I.T.E.A. 65 45-55.

Lindquist, J.L., \& Mortensen, D.A. (1999). Ecophysiological characteristics of four maize hybrids and Abutilon theophrasti. Weed Research, 39 271-285.

M.C. Donald, J. \& Riha, S.J. (1999). Model of crop:weed competition applied to maize: Abutilon theophrasti M interactions. I. Model description and evaluation. Weed Research, 39 355-369.

Patterson, D.T. (1995). Effects of photoperiod on reproductive development in velvetleaf (Abutilon theophrasti M). Weed Science, 43 627-633.

Rodriguez, D. \& Carnero, J.M. (1990). El algodón. Ed. Mundi Prensa, 242 pp.

Saavedra, M., Cortés, J.A., Gómez de Barreda, D., Rodríguez-Bernabé, J.A., Taberner, A., Castejón, M., Montserrat, A. \& Zaragoza, C. (1995). Malas hierbas de dificil control. Publicaciones del Ministerio de Agricultura, Pesca y Alimentación. 10 pp.

Sato, S., Tateno, K. \& Kobayashi, R. (1994). Influence of seeding date on flowering and seed production of 
velvetleaf (Abutilon theophrasti M.). Weed Research, 39 243-248.

Sattin, M., Zanin, G. \& Berti, A. (1992). Case history for weed competition/population ecology: Velvetleaf (Abutilon theophrasti M.) in corn (Zea mays). Weed Technology, 6 213-219.

Spencer, N.R. (1984). Velvetleaf, Abutilon theophrasti (Malvaceae). History and economic impact in the United States. Economic Botany, 38 407-416.

Stoller, E.W. \& Wax, L.M. (1973). Periodicity of germination and emergence of some annual weeds. Weed Science, 29 307-316.

Toole, E. H. \& Brown, E. (1946). Final results of the buried seed experiment. Journal of Agriculture Research, 72 201-210.

Wax, L.M. (1977). Incorporation depth and rainfall on weed control in soybean with metribuzin. Agronomy Journal, 69 107-110.

Zanin, G. \& Sattin, M. (1988). Threshold level and seed production of velvetleaf (Abutilon theophrasti Medicus) in maize. Weed Research, 28 347-352.

Table 1. Cumulative amount of heat units, expressed in growing degree-days (GDD), obtained at the times the first two cohorts of velvetleaf reached their different phenological stages in the Guadalquivir basin in 1997/98

\begin{tabular}{lcc}
\hline Stage & \multicolumn{2}{c}{ GDD } \\
\cline { 2 - 3 } & First cohort & Second cohort \\
\hline Emergence of first leave (D1) & $32 \pm 4.4$ & $45 \pm 7$ \\
End of stage Co in the population & $125 \pm 7$ & $143 \pm 3$ \\
Emergence of sixth leaf (D3) = end of rosette period (Co + D1 + D2) & $221 \pm 22$ & $222 \pm 17$ \\
Formation of earliest floral buds (E) & $448 \pm 56$ & $417 \pm 30$ \\
Onset of flowering (F) & $572 \pm 26$ & $594 \pm 22$ \\
Presence of flowers in different cohorts & $821 \pm 5$ & $827 \pm 30$ \\
Overall period with flowering overlapping in both cohorts & & $972 \pm 62$ \\
Onset of fruit growing (G) & $690 \pm 28$ & $693 \pm 15$ \\
Duration of G in each cohort & $792 \pm 60$ & $777 \pm 24$ \\
Overall length of fruit growing period in both cohorts & & $945 \pm 15$ \\
Onset of fruit ripening (H) & $885 \pm 11$ & $880 \pm 13$ \\
Overall fruit ripening period overlapping in both cohorts & & $776 \pm 59$ \\
Onset of fruit drying (I) & $1020 \pm 23$ & $1037 \pm 19$ \\
Duration of drying stage (I) in each cohort & $552 \pm 25$ & $584 \pm 29$ \\
Overall duration of drying stage (I) in both cohorts & & $700 \pm 45$ \\
\hline
\end{tabular}

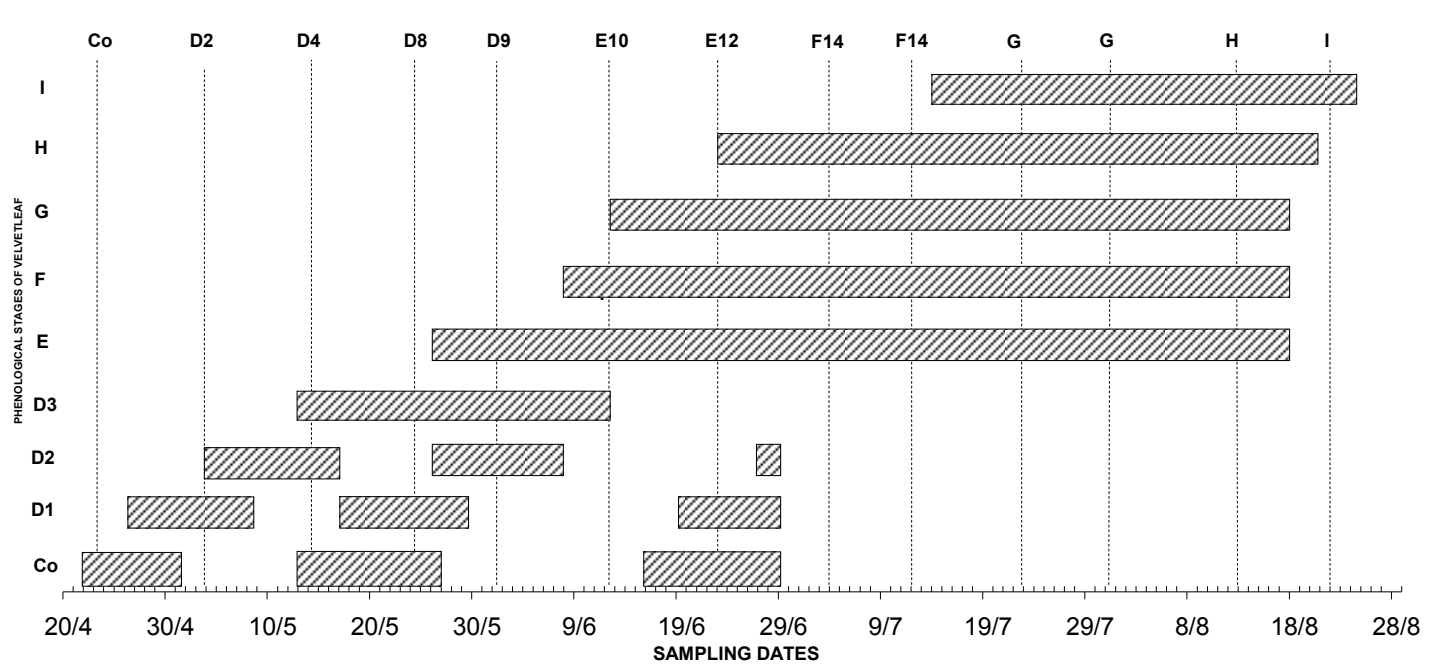

Figure 1. Evolution of the phenological stages of population of $A$. Theophrasti, sown the $15^{\text {th }}$ of april and synchronized to the one of cotton under plastic. X-axis: sampling date and mayority phenological states of cotton; Y-axis: phenology of velvetleaf 

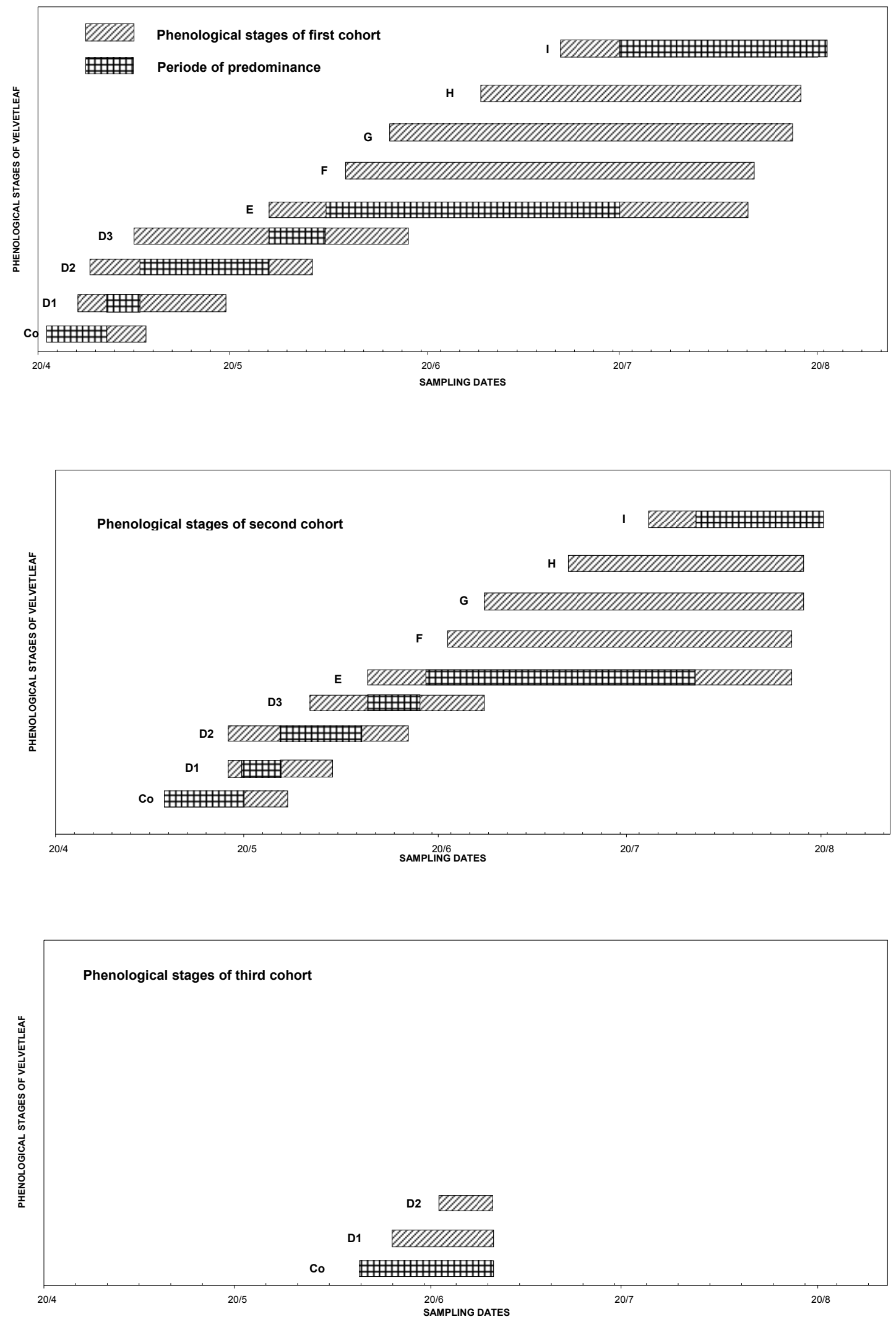

Figure 2a. Phenology development of A. theophrasti of sowing in cotton of Coria del Rio. Average data of 2001-2002 

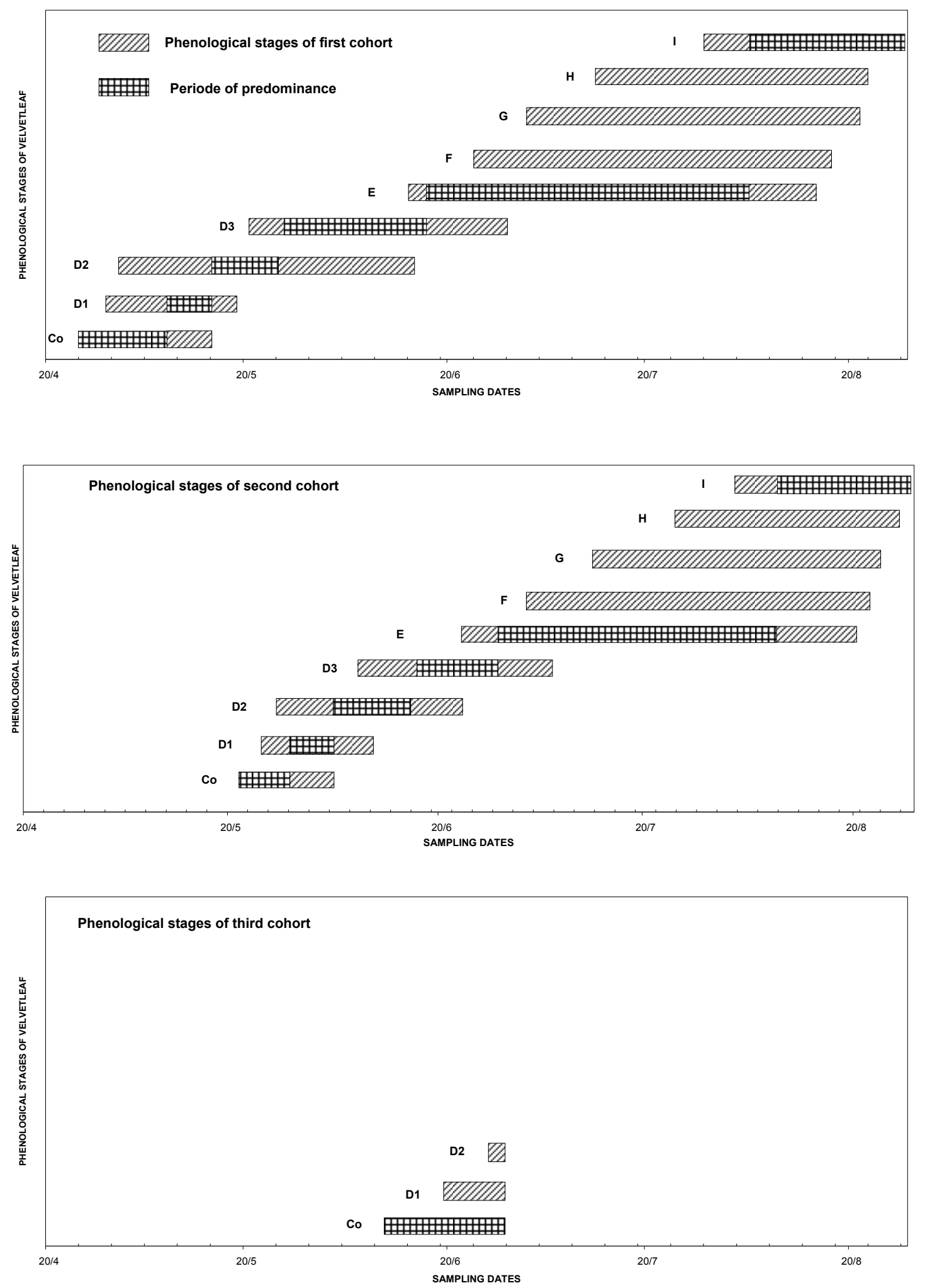

Figure 2b. Phenology development of $A$. theophrasti of sowing in cotton of Los Rosales. Average data of 2001-2002 


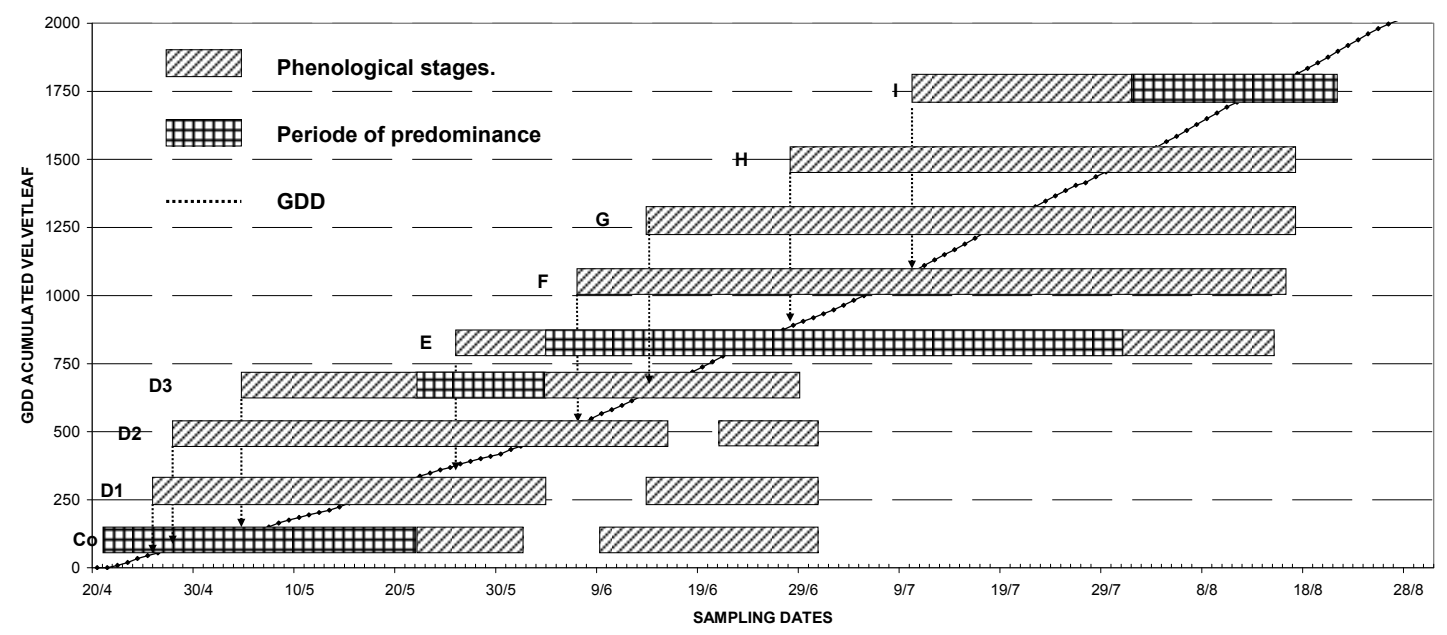

Figure 3a. Phenology of $A$. theophrasti general population, adding three cohorts. GGD of the beginning of each stage in Coria del Rio. 2001-2002. X-axis Accumulated GDD of A. theophrasti

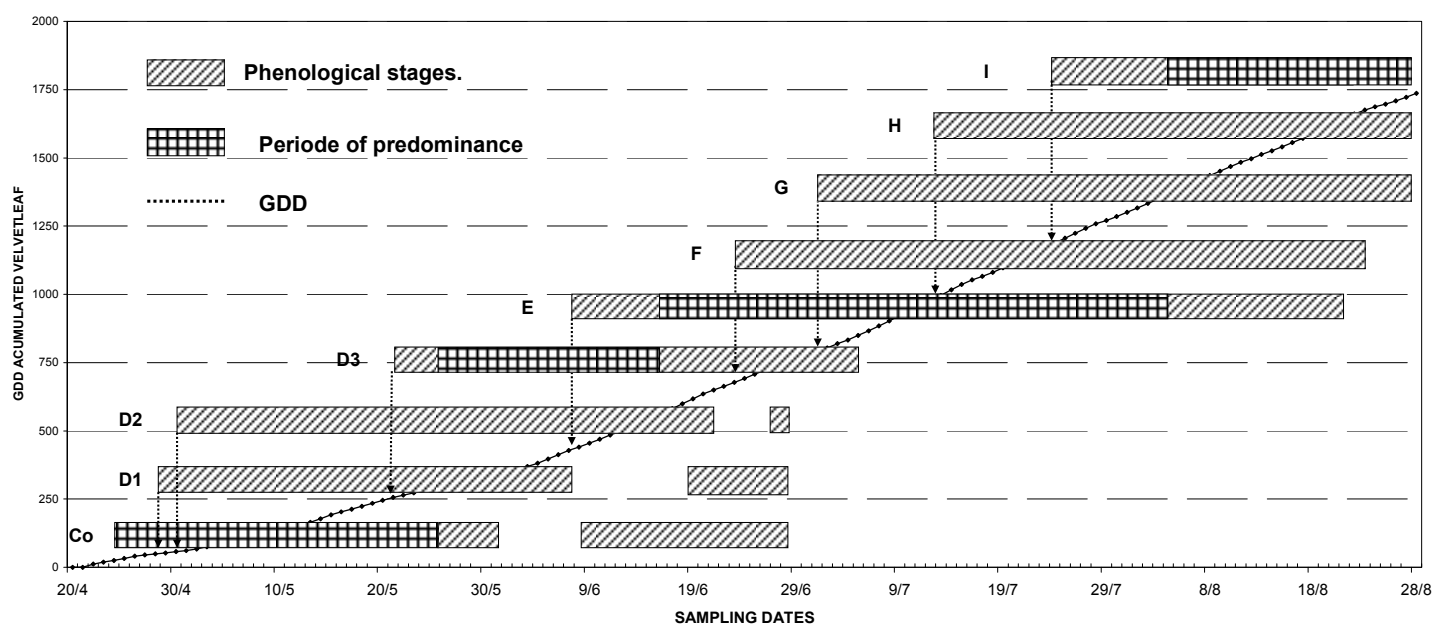

Figure $3 \mathrm{~b}$. Phenology of $A$. theophrasti general population, adding three cohorts. GGD of the beginning of each stage in Los Rosales. 2001-2002. X-axis Accumulated GDD of $A$. theophrasti 
a) Rosette 1-5 leaves (D1+D2).

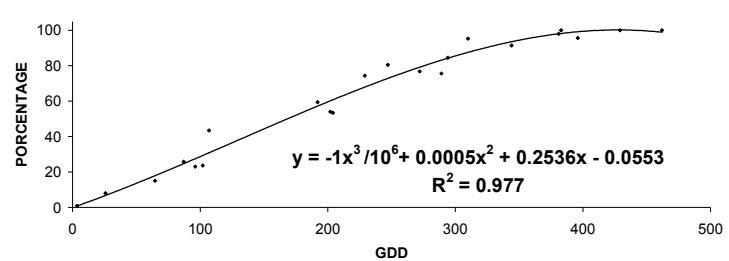

c) Flowering (F).

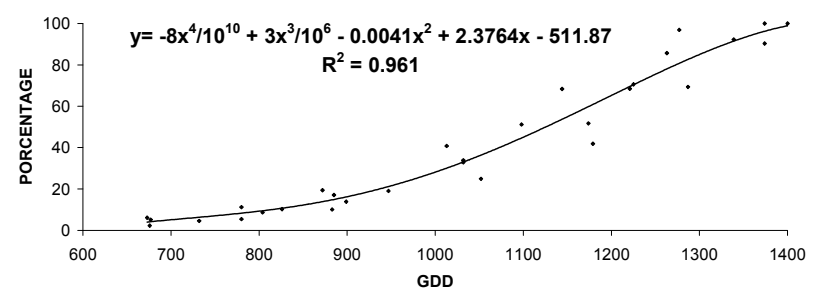

e) Fruits drying (I).

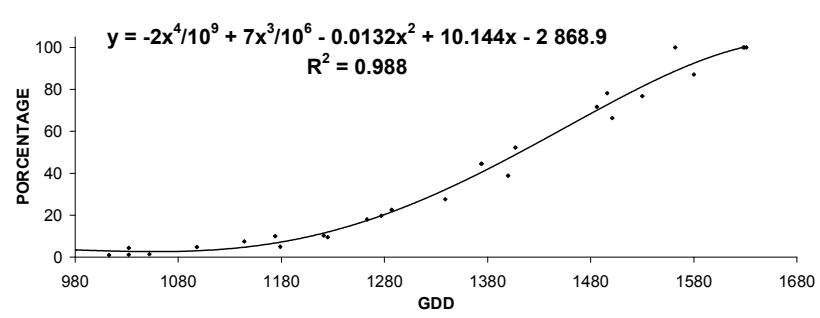

b) Extension (D3).

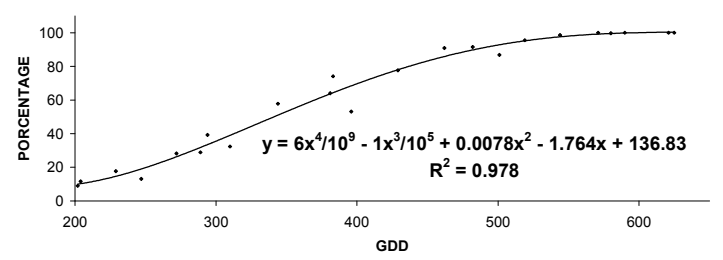

d) Ripening fruits $(\mathrm{H})$.

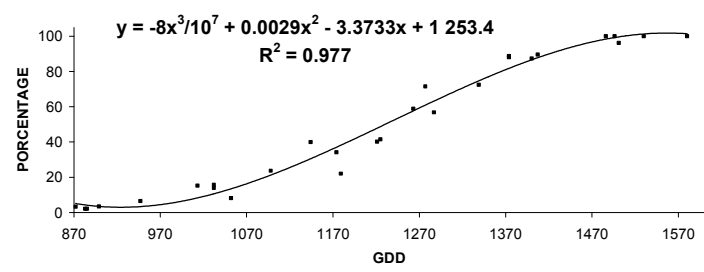

Polinomial ecuations:

F between $600 / 1.400$ GDD

$\mathrm{H}$ between $670 / 1.570$ GDD

I between 980 / 1.680

Figure 4a. Phenological of 1 th cohort of $A$. theophrasti based on accumulated GDD. X-axis GDD; Y-axis percentage 
a) Rosette 1-5 leaves.

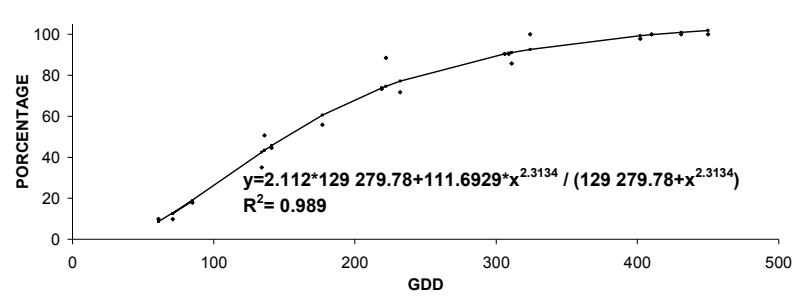

c) Flowering (F).

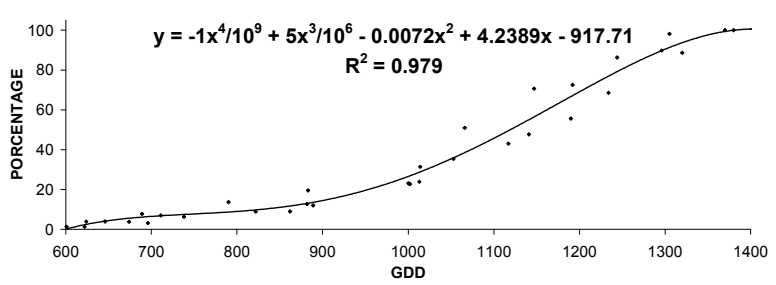

e) Fruits drying (I)

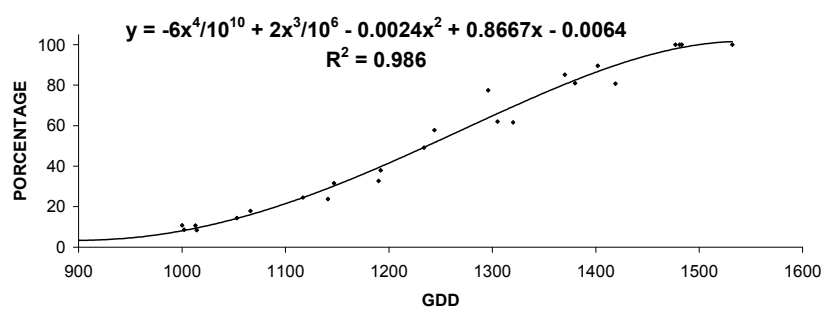

b) Extension (D3)

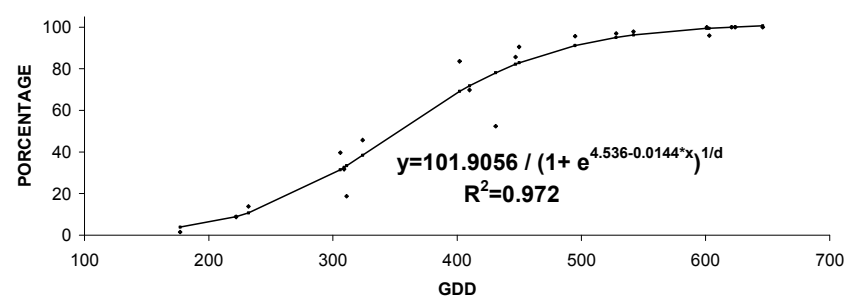

d) Ripening fruits $(\mathrm{H})$.

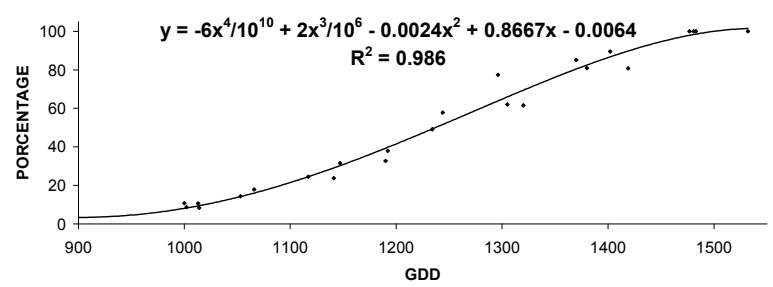

Polinomial ecuations:

F between $600 / 1.400$ GDD

H between 670 / 1.570 GDD

Figure 4b. Phenological of 2th cohort of $A$. theophrasti based on accumulated GDD. X-axis GDD; Y-axis percentage 
a) Density $0 \mathrm{pl} / \mathrm{m} . \mathrm{l}$. velvetleaf

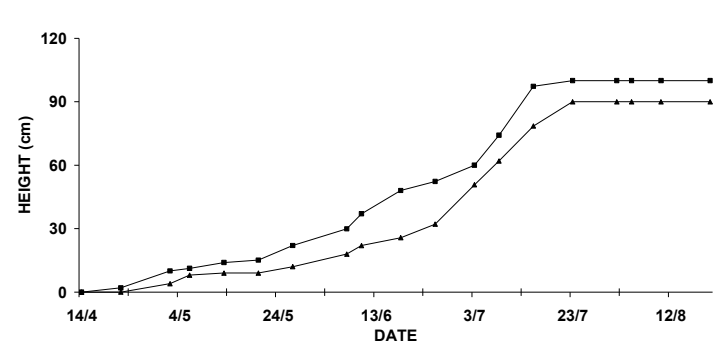

c) Density $2 \mathrm{pl} / \mathrm{m} . \mathrm{l}$. velvetleaf.

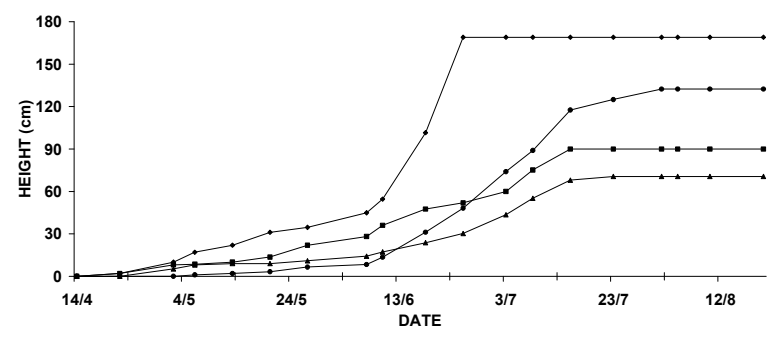

e) Density $11 \mathrm{pl} / \mathrm{m}$. I velvetleaf.

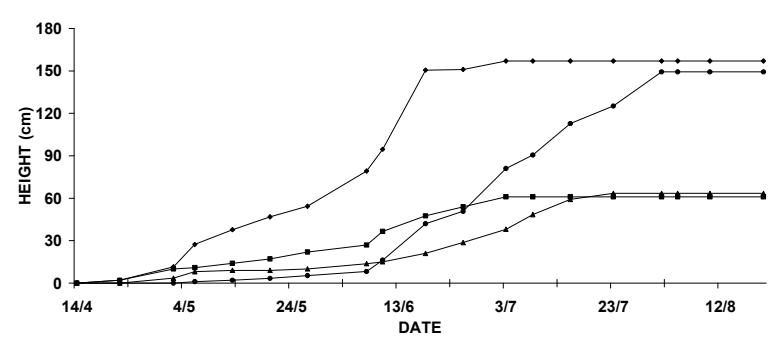

b) Density $1 \mathrm{pl} / \mathrm{m} . \mathrm{l}$. velvetleaf.

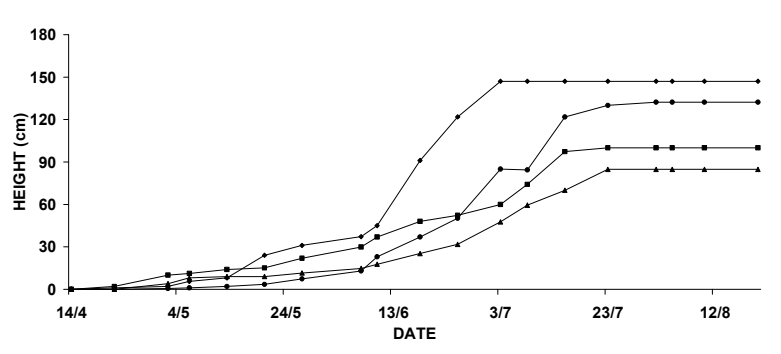

d) Density $5 \mathrm{pl} / \mathrm{m} . \mathrm{l}$. velvetleaf

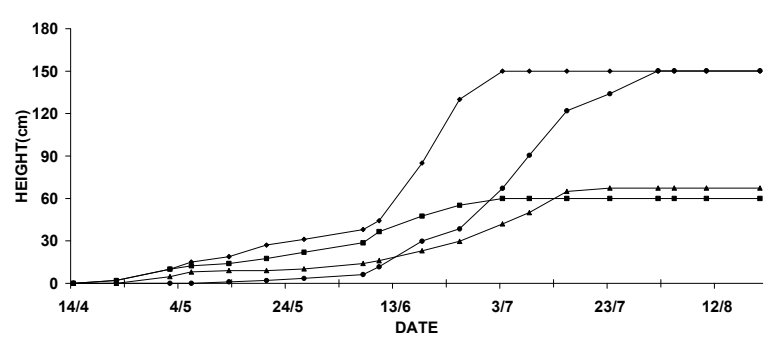

f) Density $25 \mathrm{pl} / \mathrm{m} . \mathrm{l}$. velvetleaf.

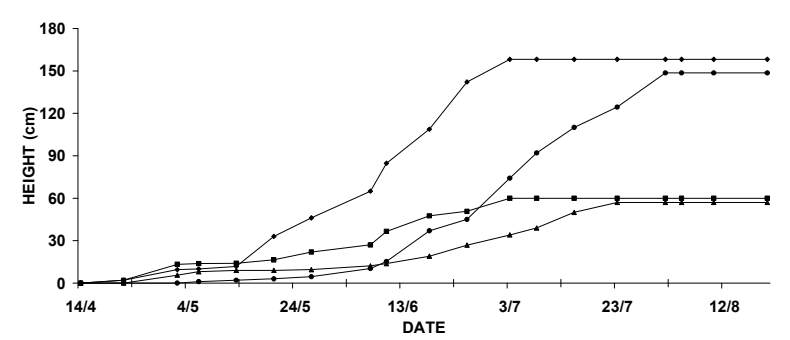

Figure 5a. Evolution of the height of cotton and velvetleaf seeded simultaneously, with different densities of weeds. Coria 2001/2002 
a) Density $0 \mathrm{pl} / \mathrm{m} . \mathrm{I}$. velvetleaf.

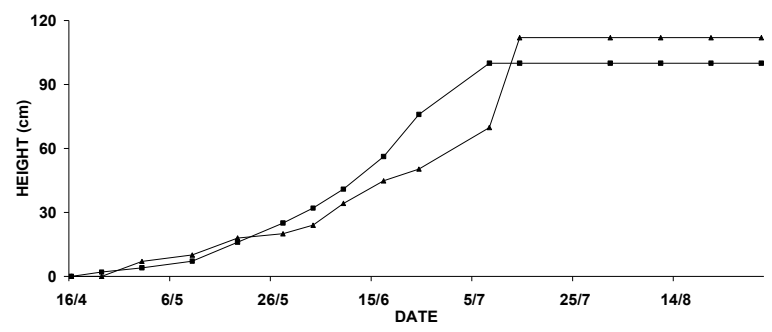

c) Density $2 \mathrm{pl} / \mathrm{m} . \mathrm{l}$. velvetleaf

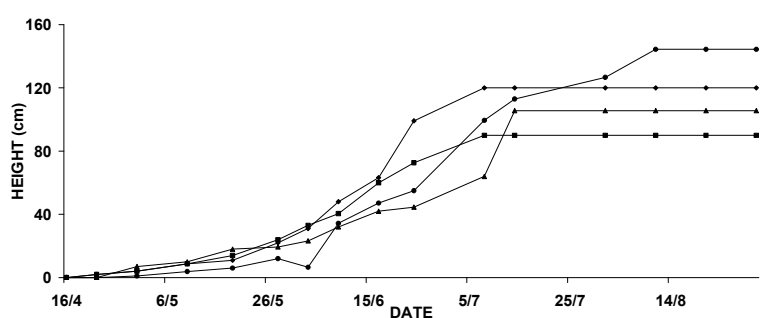

e) Density $11 \mathrm{pl} / \mathrm{m} . \mathrm{l}$. velvetleaf.

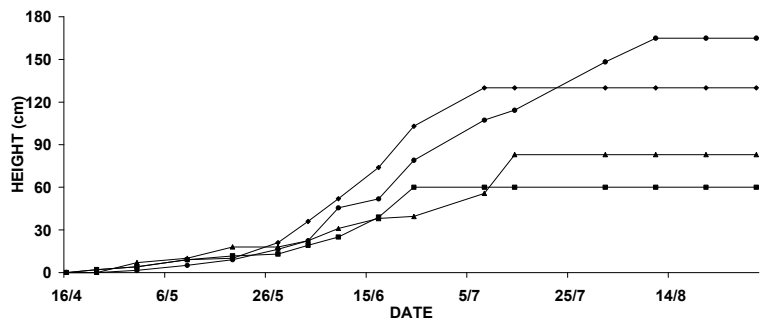

b) Density $1 \mathrm{pl} / \mathrm{m} . \mathrm{I}$. velvetleaf.

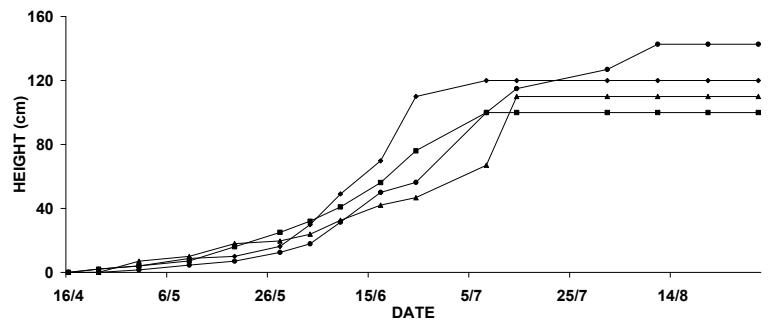

d) Density $5 \mathrm{pl} / \mathrm{m} . \mathrm{l}$. velvetleaf

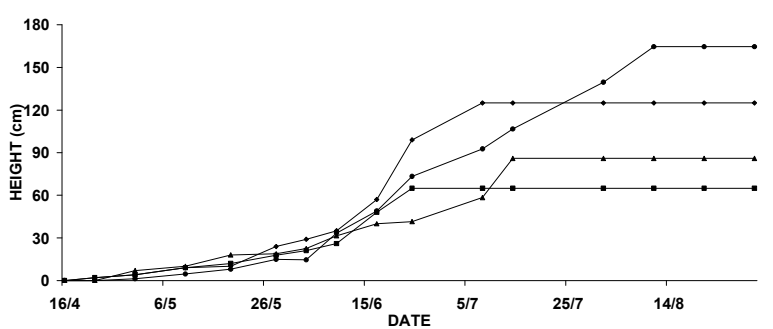

f) Density 25 pl/m.l. velvetleaf

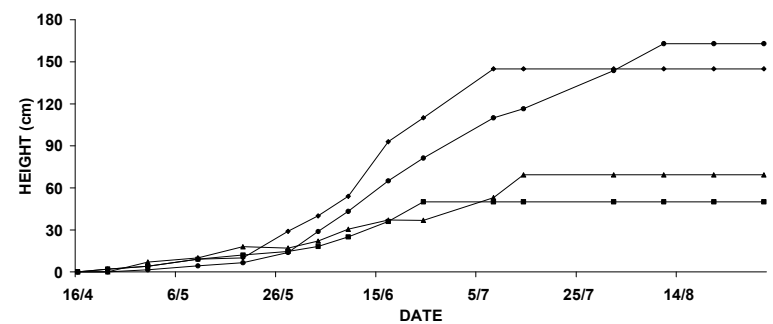

Figure $5 \mathrm{~b}$. Evolution of the height of cotton and velvetleaf seeded simultaneously, with different densities of weeds. Los Rosales 2001/2002 